\title{
The calcium-modulated proteins, S100A1 and S100B, as potential regulators of the dynamics of type III intermediate filaments
}

M. Garbuglia, M. Verzini, G. Sorci, R. Bianchi,

I. Giambanco, A.L. Agneletti and R. Donato
Section of Anatomy, Department of Experimental Medicine and

Biochemical Sciences, University of Perugia, Perugia, Italy

\section{Correspondence}

R. Donato

Section of Anatomy

Department of Experimental Medicine

and Biochemical Sciences

University of Perugia

Via del Giochetto, C.P. 81 Succ. 3

06122 Perugia

Italy

Fax: + 39-075-585-3451

E-mail: donato@unipg.it

Presented at the XXVIII Annual

Meeting of the Brazilian Society

of Biochemistry and Molecular

Biology, Caxambu, MG, Brasil,

May 22-25, 1999.

Research supported by TelethonItaly (Project No. 922) and a European Community grant (Contract No. BIO 4CT960083) to R. Donato

Received June 30, 1999 Accepted July 12, 1999

\section{Abstract}

The $\mathrm{Ca}^{2+}$-modulated, dimeric proteins of the EF-hand (helix-loophelix) type, S100A1 and S100B, that have been shown to inhibit microtubule (MT) protein assembly and to promote MT disassembly, interact with the type III intermediate filament (IF) subunits, desmin and glial fibrillary acidic protein (GFAP), with a stoichiometry of 2 mol of IF subunit/mol of S100A1 or S100B dimer and an affinity of $0.5-1.0 \mu \mathrm{M}$ in the presence of a few micromolar concentrations of $\mathrm{Ca}^{2+}$. Binding of S100A1 and S100B results in inhibition of desmin and GFAP assemblies into IFs and stimulation of the disassembly of preformed desmin and GFAP IFs. S100A1 and S100B interact with a stretch of residues in the N-terminal (head) domain of desmin and GFAP, thereby blocking the head-to-tail process of IF elongation. The C-terminal extension of S100A1 (and, likely, S100B) represents a critical part of the site that recognizes desmin and GFAP. S100B is localized to IFs within cells, suggesting that it might have a role in remodeling IFs upon elevation of cytosolic $\mathrm{Ca}^{2+}$ concentration by avoiding excess IF assembly and/or promoting IF disassembly in vivo. S100A1, that is not localized to IFs, might also play a role in the regulation of IF dynamics by binding to and sequestering unassembled IF subunits. Together, these observations suggest that S100A1 and S100B may be regarded as $\mathrm{Ca}^{2+}$-dependent regulators of the state of assembly of two important elements of the cytoskeleton, IFs and MTs, and, potentially, of MT- and IF-based activities.

\section{Introduction}

Intermediate filaments (IFs) constitute a major cytoskeleton component of most, if not all, eukaryotic cells (1-5). IFs, which have been subdivided into several major types depending on their subunit composition and

\section{Key words}

- S100A1

- S100B

- Intermediate filaments

- Calcium

- Regulatory effects

- Assembly-disassembly 
obligatory heteropolymers) in which dimers made of parallel and in register monomers associate to form tetramers in which couples of dimers are arranged in a staggered and antiparallel manner (Figure 1A). Tetramers then form octamers through lateral associations and elongate via a head-to-tail mech-

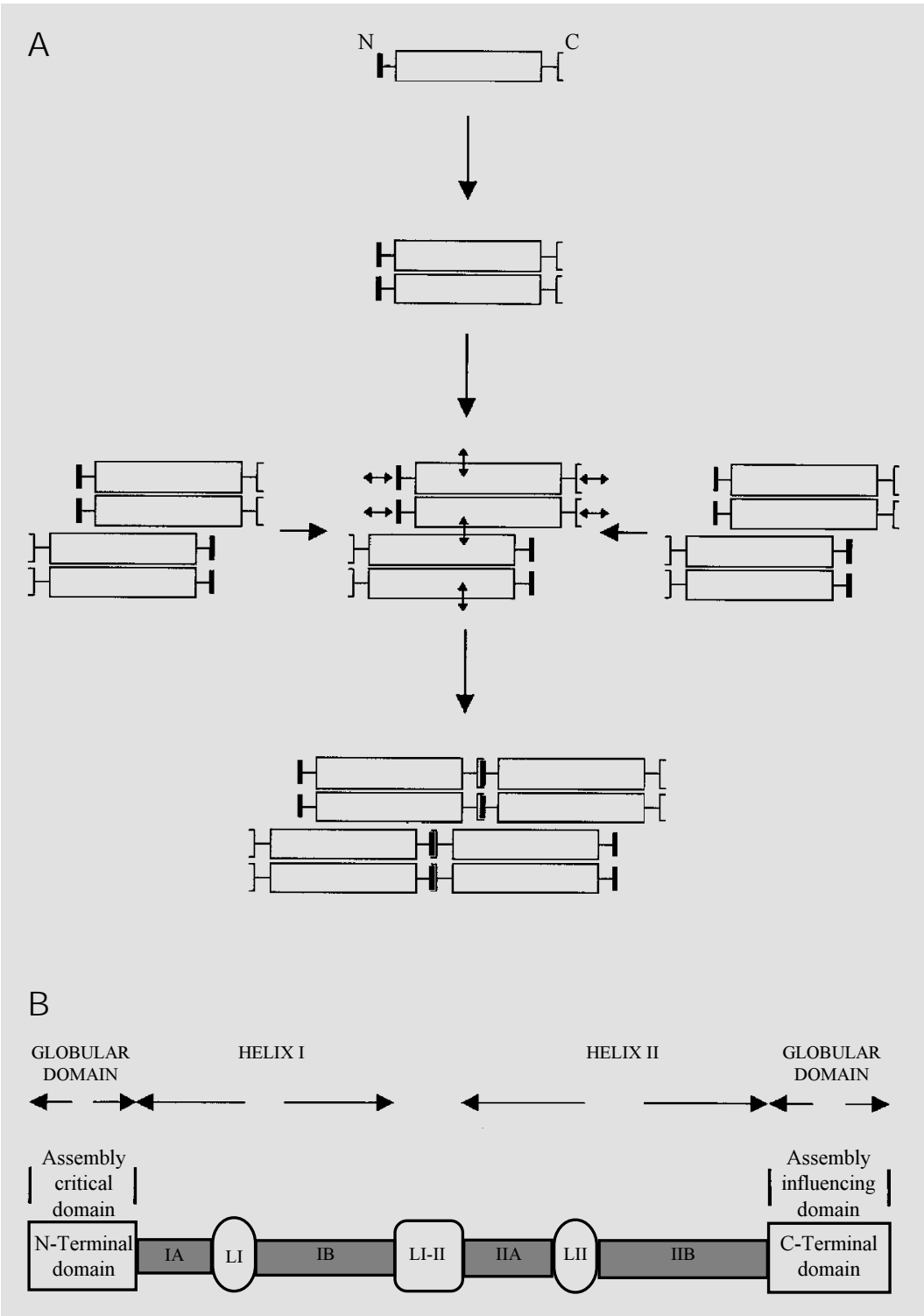

Figure 1 - A, Schematic representation of association of intermediate filament (IF) subunits into dimers, tetramers, and octamers. In IF dimers monomers are found parallel and in register, and association of monomers into dimers takes place through their rod domains. IF tetramers form through the lateral association of dimers, but here dimers are antiparallel and staggered. Filament elongation occurs via a head-to-tail mechanism. B, Schematic representation of an IF subunit. A core domain (rod) is flanked by a head (N-terminal) domain and a tail (C-terminal) domain. The head domain is critically important for filament assembly (elongation) (see Refs. 1-5 for reviews). anism (Figure 1A). Typically, an IF subunit consists of a conserved central core (rod domain) composed of two helical regions periodically interrupted by short, non-helical stretches, that is flanked by an N-terminal (head) domain and a C-terminal (tail) domain (Figure 1B). The N-terminal domain is critical for filament elongation, whereas the C-terminal domain appears less critical. Rather, a stretch of residues found in the $\mathrm{C}$ terminus of the rod domain appears important for IF formation. The rod domain is responsible for lateral association of subunits into dimers/tetramers/octamers (1-5).

IFs have been long considered as static cytoskeleton elements owing to their resistance to extraction with non-ionic detergents in the presence of high concentrations of $\mathrm{KCl}$ and their solubility in high concentrations of urea (1-5). In recent years, however, in vitro and in vivo evidence has been provided showing that IFs coexist with a pool of unassembled subunits and that polymerized subunits exchange with their unpolymerized counterparts (6-11), i.e., IFs undergo assembly-disassembly depending on cell needs and/ or functional states. Phosphorylation is among the factors that play an important role in remodeling IFs. Phosphorylation of preformed IFs results in disassembly and phosphorylation of unassembled subunits renders them assembly-incompetent (12-17). Several kinases can act to regulate the IF dynamics, and at the onset of mitosis a specific kinase (cdc2 kinase) is expressed that phosphorylates preformed IFs (12-17). This process is functional to the shape changes that occur at the onset of mitosis when IFs disassemble and reassemble to form a cagelike structure around chromosomes and the mitotic spindle of daughter cells (12-17).

However, it is reasonable to assume that IF remodeling also occurs in non-dividing cells during locomotion and/or at cell sites where the cell needs to be less rigid in order to accomplish specific functions. In this regard, factors other than kinases have been 
postulated to exist that contribute to modifying the topographical distribution and the tridimensional organization of IFs via disassembly and reassembly (3).

\section{S100 proteins}

S100A1 and S100B are members of a multigenic family of $\mathrm{Ca}^{2+}$-modulated proteins of the EF-hand (helix-loop-helix) type that comprises 19 members showing 25 to $65 \%$ sequence identity. S100 proteins have been implicated in the regulation of several activities such as protein phosphorylation, the cell cycle, $\mathrm{Ca}^{2+}$ homeostasis, the dynamics of cytoskeleton elements, and enzyme activities (18-22). With the exception of calbindin $\mathrm{D}_{9 \mathrm{k}}$, which is a $\mathrm{Ca}^{2+}$ modulator protein implicated in buffering cytosolic $\mathrm{Ca}^{2+}$, all other $\mathrm{S} 100$ members are considered $\mathrm{Ca}^{2+}$ sensor proteins implicated in $\mathrm{Ca}^{2+}$ signal transduction via their interaction with definite target proteins. Each S100A1 or S100B polypeptide chain $\left(\mathrm{M}_{\mathrm{r}} \approx 10 \mathrm{kDa}\right)$ (like any other $\mathrm{S} 100$ member) contains two $\mathrm{Ca}^{2+}$-binding loops, one in the $\mathrm{N}$-terminal half and the other one in the C-terminal half, each of which is flanked by $\alpha$-helices for a total of four helices (helix I to helix IV)/molecule $(23,24)$ (Figure 2). The $\mathrm{Ca}^{2+}$-binding loop in the N-terminal half of the chain is non-conventional (longer and rearranged) and binds $\mathrm{Ca}^{2+}$ with low affinity, whereas the $\mathrm{Ca}^{2+}$ binding loop in the C-terminal half is canonical and binds $\mathrm{Ca}^{2+}$ with a relatively high affinity. The two EF-hands are connected by a linker (the hinge region), and helix IV is followed by a C-terminal extension (Figure 2 ). The two proteins display $56 \%$ sequence identity, with the highest amount of identity in the EF-hands and the least amount in the hinge region and the $\mathrm{C}$-terminal extension. It is suggested that differences in sequence and length of these two regions specify the biological activities of S100A1 and S100B (and other S100 members) (18-22).

S100A1 is most abundant in slow-twitch skeletal muscle cells, some epithelial cells, and some neuronal populations, whereas S100B is most abundant in glial cells, melanocytes, chondrocytes, adipocytes, and neuronal subpopulations (18-22). By immunocytochemistry at both the light and the electron microscope levels, S100B has been localized to IFs, axonemal microtubules (MTs), centrioles, the centrosomes, the midbody, some cytoplasmic MTs, and intracellular membranes in glial cells and several cell lines (25-28), whereas S100A1 has been localized to intracellular membranes, including the triads, in skeletal muscle cells, and close to Z-discs in sarcomeres $(29,30)$.

Within cells, S100A1 and S100B exist as homodimers (with a small fraction of S100A1/S100B heterodimers) in which the two monomers are held together by noncovalent bonds between helices IV and IV' and helices I and I', with some contribution by C-terminal extensions, and are related by a two-fold axis of rotation (31-34). A similar configuration has been detected in other $\mathrm{S} 100$ members $(35,36)$, suggesting that the $\mathrm{S} 100$ proteins that dimerize share a common structural motif. However, given the differences in sequence and length of the hinge region and the C-terminal extension and the orientation of helices in individual S100 proteins, it is conceivable that each of these might be implicated in the regulation of specific activities by interacting with definite target proteins (18-22).

Upon $\mathrm{Ca}^{2+}$ binding, the most dramatic change in the $\mathrm{S} 100 \mathrm{~B}$ structure is a reorientation of helix III with a consequent reorienta-

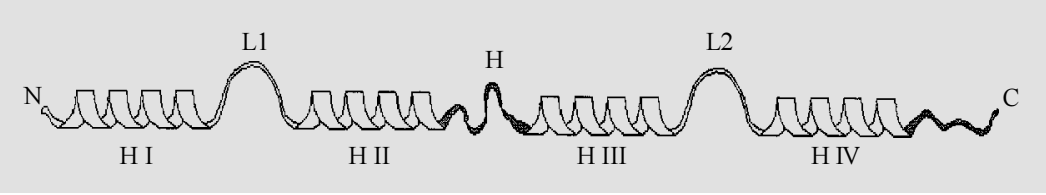

Figure 2 - Schematic representation of the secondary structure of an S100 protein. Each $\mathrm{Ca}^{2+}$-binding loop ( $\mathrm{L} 1$ and $\mathrm{L} 2$, in the $\mathrm{N}$ - and the C-terminal half, respectively) is flanked by $\alpha$ helices (helices I and II, and helices III and IV for L1 and L2, respectively). A linker region (hinge region, H) connects helix II to helix III. Helix IV is followed by a C-terminal extension. The hinge region and the C-terminal extension (in black) display the least amount of sequence homology among the S100 members (see Refs. 18-24). 
tion of the hinge region $(33,37,38)$. As a result, a wide cleft forms that is defined by residues in the hinge region, helix III, helix IV and the C-terminal extension, which form an ample surface believed to mediate the interaction with target proteins. It is suggested that analogous changes take place in all other S100 members that dimerize and act via an interaction with target proteins in a $\mathrm{Ca}^{2+}$-dependent manner. Since in each S100 dimer the above binding surfaces are found on opposite sides, an S100 dimer might functionally crossbridge two homologous or heterologous target proteins. Clearly, this mode of interaction is different from that of other EF-hand proteins such as calmodulin and troponin C; the two halves (lobes) of calmodulin or troponin $\mathrm{C}$ wrap around one molecule of a definite target protein, whereas S100 dimers open up and bind couples of target proteins on opposite sides (39-41).

\section{S100B and S100A1 regulate the dynamics of microtubules}

Several S100 proteins have been shown to be localized to cytoskeleton constituents, to translocate to cytoskeleton elements upon elevation of cytosolic $\mathrm{Ca}^{2+}$, and to interact with cytoskeletal proteins, suggesting that some $\mathrm{S} 100$ members might have a role in the regulation of cell shape changes, locomotion, and the tridimensional organization of the cytoskeleton (18-22). Previous studies have shown that S100B and S100A1 inhibit the assembly of MT protein and greatly increase the $\mathrm{Ca}^{2+}$-sensitivity of preformed MTs, in vitro (42-47). Specifically, S100B and S100A1 were shown to bind to and to sequester unassembled tubulin, thereby inhibiting MT formation, and to interact with the MT wall, thereby causing a rapid disassembly, in a $\mathrm{Ca}^{2+}$ - and $\mathrm{pH}$-dependent manner. However, whereas S100B is found associated with MTs in vivo (25-28), S100A1 is not $(28,48)$, pointing to differences in the mechanism of action of individual proteins on MT dynamics. S100B and S100A1 might have a role in avoiding excess MT formation and/or participate in MT disassembly at the onset of mitosis or at discrete sites in nondividing cells. Also, since S100B and S100A1 are also found associated with internal membranes, including Golgi membranes (2528,48 ), they might have a role in MT-membrane interactions that are relevant in the regulation of MT-endosome interactions, which are considered to be important in the mechanism of fusion of endosomes (49), transport from early endosomes to late endosomes (50), and apical recycling (51).

\section{S100B and S100A1 regulate the dynamics of intermediate filaments}

The observation that $\mathrm{S} 100 \mathrm{~B}$ is also found associated with IFs in glial cells $(26,27,52)$ prompted a study of possible regulatory effects of this protein as well as of S100A1 on glial and skeletal muscle IFs. The IF subunits in mature glial and skeletal muscle cells are glial fibrillary acidic protein (GFAP) and desmin, respectively, both of which belong to type III IFs (1-5). By a number of experimental approaches (a sedimentation assay, viscometry, turbidimetry, and electron microscopy), S100B and S100A1 were shown to inhibit the assembly of GFAP and desmin into their respective IFs in a dose- and $\mathrm{Ca}^{2+}$ dependent manner and to stimulate the polymerized-unpolymerized subunit exchange in vitro, i.e., to cause IF disassembly (53-56). Effects of both $\mathrm{S} 100$ proteins were shown to occur in the presence of a few micromolar concentrations of $\mathrm{Ca}^{2+}$, suggesting that the two proteins might have a role in IF remodeling upon elevation of the cytosolic $\mathrm{Ca}^{2+}$ concentration in vivo. S100B and S100A1 caused the critical concentration for IF assembly to increase and reduced the IF number concentration, pointing to an inhibitory effect on IF nucleation. The remarkable decrease in mean IF length and the ability of either S100 protein to stop the IF assembly 
when added to growing IFs suggest that both S100B and S100A1 also interfere with the IF elongation process (53-56).

By chemical crosslinking and fluorescent spectroscopy S100B and S100A1 were shown to bind reversibly to unassembled GFAP and desmin with a stoichiometry of 2 $\mathrm{mol}$ of IF subunit/mol of S100 dimer with an affinity of $0.5-1.0 \mu \mathrm{M}$, in agreement with the notion that an S100 dimer has two binding surfaces on opposite sides $(53,56)$.

Several lines of evidence suggest that S100B and S100A1 interact with the Nterminal head of both GFAP and desmin, thereby sequestering unassembled subunits and blocking the head-to-tail association of subunits into IF polymers $(53,56-58)$ (Figure 3). 1) Neither headless GFAP or desmin nor headless/tailless GFAP or desmin (i.e., their rod domain) as obtained by enzymatic cleavage was able to interact with either S100 protein. 2) By chemical crosslinking, heterocomplexes made of two copies of GFAP or desmin plus two copies of S100B or $\mathrm{S} 100 \mathrm{~A} 1$, in addition to complexes made of $1 \mathrm{~mol}$ of S100 monomer plus $1 \mathrm{~mol}$ of GFAP or desmin, could be resolved by Western blotting using a polyclonal anti-S100B/ A1 antiserum. 3) The synthetic peptide, TRTK-12 (TRTKIDWNKILS), corresponding to a consensus sequence found in another S100B- and S100A1-target protein, i.e., the $\alpha$-subunit of the actin capping protein, CapZ, and able to compete with CapZ $\alpha$ for binding to either $\mathrm{S} 100$ protein $(59,60)$, displayed a high sequence identity with a stretch of residues found in the N-terminal head of GFAP containing the so-called RPbox motif shown to be critical for GFAP (as well as desmin and vimentin) assembly. 4) TRTK-12 competed with GFAP or desmin for binding to S100B or S100A1 and blocked the ability of either S100 member to inhibit the GFAP and desmin assemblies and to stimulate GFAP and desmin IF disassembly, in a dose- and $\mathrm{Ca}^{2+}$-dependent manner. Incidentally, these observations strongly suggest that those proteins that contain the CapZ $\alpha$ consensus sequence $(\mathrm{K} / \mathrm{R})(\mathrm{L} / \mathrm{I}) X \mathrm{~W} X X \mathrm{IL}$ might be S100B- and S100A1-binding proteins; in fact, other S100B and S100A1 target proteins (i.e., neurogranin, neuromodulin/ GAP-43, p53, caldesmon) were shown to contain the above consensus sequence (22). Also, these observations strongly suggest that S100B and S100A1 use the same site for recognizing those target proteins that share the above consensus sequence.
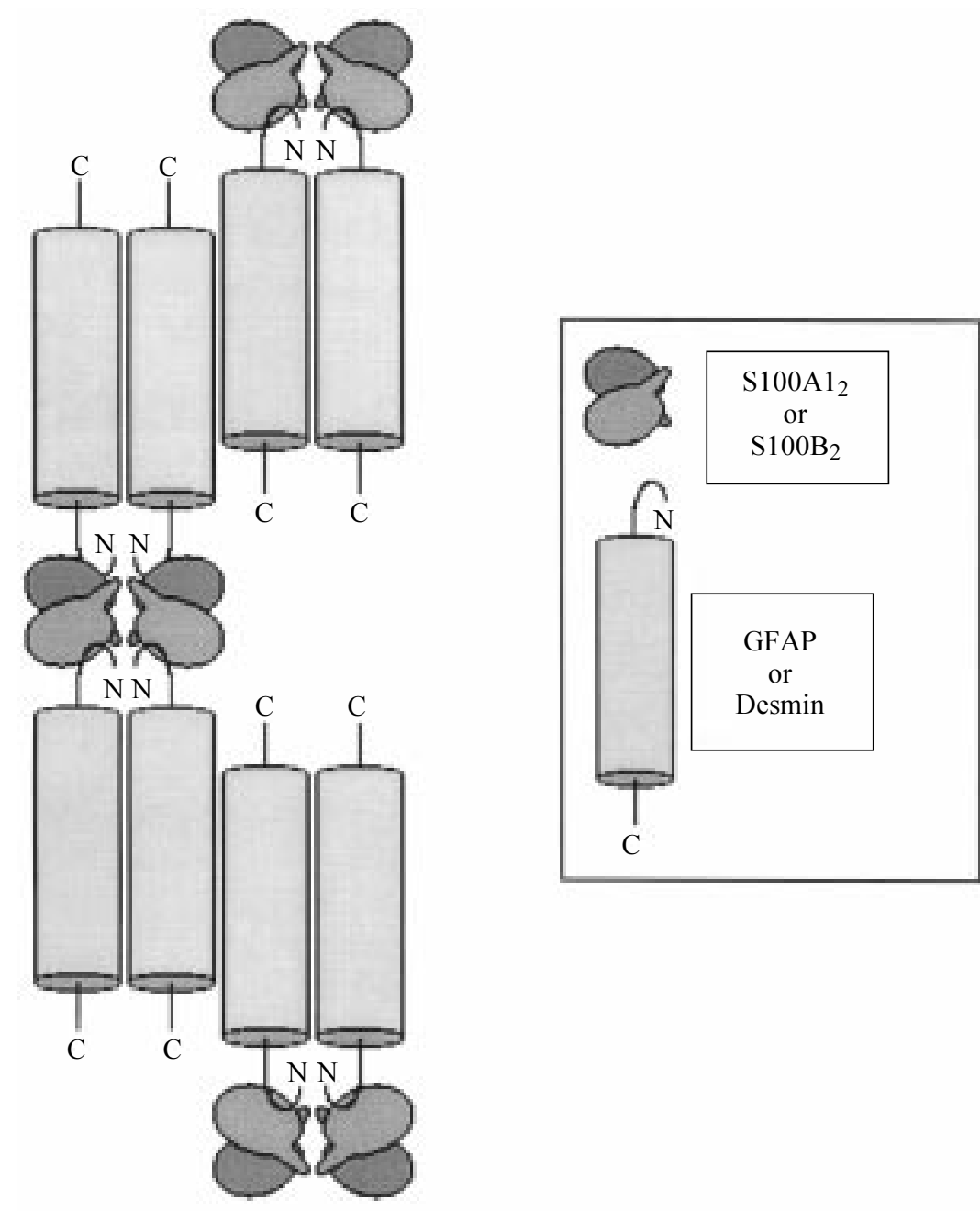

Figure 3 - Schematic representation of the $\mathrm{Ca}^{2+}$-dependent interaction between $\mathrm{S} 100 \mathrm{Al}_{2}$ or $\mathrm{S} 100 \mathrm{~B}_{2}$ dimers and desmin or glial fibrillary acidic protein (GFAP) tetramers. A pair of $\mathrm{S} \mathrm{SO}_{2}$ dimers crossbridges two desmin or GFAP dimers by interacting with the desmin or GFAP N-terminal domain. Binding of either S100 protein to the N-terminal domain results in inhibition of desmin or GFAP assembly into type III intermediate filaments. Formation of macrocomplexes composed of four desmin or GFAP subunits plus four copies of S100A1 or S100B monomers was observed by chemical crosslinking (see Refs. 57,58). 
Annexin VI and annexin V, two members of a multigenic family of $\mathrm{Ca}^{2+}$-dependent phospholipid-, membrane- and cytoskeleton-binding proteins $(61,62)$, bind to S100A1 and S100B, but only annexin VI blocks the ability of the two $\mathrm{S} 100$ proteins to inhibit GFAP and desmin assemblies, in a $\mathrm{Ca}^{2+}$ - and dose-dependent manner (63). In those cells that co-express S100A1 or S100B, and annexin VI, the latter might act as a regulator of S100A1/S100B effects.

Recent evidence suggests that the C-terminal extension of S100A1 (and, by analogy, S100B) is critically implicated in the recognition of GFAP (as well as CapZ $\alpha$, desmin, tubulin, p53) (64). In fact, a mutant S100A1 lacking the C-terminal extension (S100A1 $\Delta 88-93)$, that was shown to form homodimers, to undergo $\mathrm{Ca}^{2+}$-dependent conformational changes, and to bind to phenylSepharose in a $\mathrm{Ca}^{2+}$-dependent manner $(64,65)$, proved unable to interact with GFAP, tubulin, p53 and TRTK-12, and to inhibit GFAP assembly.

On the basis of the above data, we suggest that couples of S100B or S100A1 homodimers (and, eventually, S100B/S100A1 heterodimers) functionally crossbridge couples of GFAP or desmin dimers on opposite sides via interaction of their C-terminal extensions with the GFAP or desmin N-terminal domain, thereby blocking the head-totail mechanism of IF subunit elongation, as mentioned above (Figure 3). At present we do not know whether or not other regions of the binding surface identified in $\mathrm{Ca}^{2+}$-loaded S100B or S100A1 take part in the recognition of type III IF subunits.

\section{Does S100B or S100A1 have a role in type III IF dynamics in vivo?}

S100B, but not S100A1 was localized to GFAP, vimentin and desmin IFs in several cell lines as well as to GFAP IFs in Müller cells in bovine retina, and was observed to follow the destiny of these IFs after cell treatment with colchicine, taxol, cold, or inhibitors of phosphatases (all conditions that cause a dramatic rearrangement of IFs or, in the case of phosphatase inhibitors, IF disassembly and condensation of residual IFs in a paranuclear structure also containing MTs) $(27,28,52)$. Also, at several cell sites MTs with their attached S100B appear surrounded and/or flanked by IFs with their attached S100B (32).

Thus, S100B seems strategically positioned along IFs and MTs possibly to contribute to crossbridging of IFs to MTs and/or to take part in the regulation of the dynamics of these cytoskeleton constituents. Also, S100B inhibits GFAP and vimentin phosphorylation (66), which might be a reflection of S100B ability to interact with the N-terminal domain of type III IFs and/or represent a means of regulating their assembly-disassembly. Lastly, astrocytes in the brain of mutant mice expressing a much reduced amount of S100B exhibit larger amounts of GFAP IFs (67), a finding that has been related (67) to the ability of S100B to inhibit GFAP IF assembly.

Together with the in vitro data mentioned above, all of these findings suggest that one biological role of S100B is to contribute to the regulation of the state of assembly of several cytoskeleton constituents. The high abundance of S100B in a number of cell types, including glial cells (where S100B concentration may be as high as $10-20 \mu \mathrm{M}$ ) (68), renders such a role possible. Instead, S100A1, which has not been found associated with either MTs or IFs in vivo, might contribute to MT and IF remodeling via an interaction with unassembled tubulin or IF subunits. Interestingly, recent evidence suggests that: i) both S100B and S100A1 cause MT disassembly and/or fragmentation when added to triton-cytoskeletons obtained from glial, myoblast and renal cell lines, in a $\mathrm{Ca}^{2+}$ dependent manner, whereas S100A1 $\Delta 88-93$ is without effects, in agreement with the finding that S100B and S100A1 interact with 
the MT wall, thereby increasing the $\mathrm{Ca}^{2+}$ sensitivity of MTs and both proteins use their C-terminal extension for binding to tubulin; ii) no obvious IF disassembly can be observed under these conditions, further supporting the conclusion that $\mathrm{S} 100 \mathrm{~B}$ and S100A1 cause IF disassembly by sequestering unassembled IF subunits, and iii) some bundling of IFs can be observed under these conditions due to disruption of the MT network (Sorci G, Agneletti AL and Donato R, unpublished data).

It would be of interest to analyze the effects of overexpression or inhibition of S100B expression in terms of number, distribution and total mass of MTs and IFs in resting, activated and dividing cells.

\section{References}

1. Albers K \& Fuchs E (1992). The molecular biology of intermediate filaments. International Review of Cytology, 134: 243279.

2. Parry DAD \& Steinert PM (1992). Intermediate filament structure. Current Opinion in Cell Biology, 4: 94-98.

3. Georgatos SD (1993). Dynamics of intermediate filaments. Recent progress and unanswered questions. FEBS Letters, 318: 101-107.

4. Fuchs E \& Weber K (1994). Intermediate filaments: structure, function, and disease. Annual Review of Biochemistry, 63: 345-382.

5. Hermann H \& Aebi U (1998). Intermediate filament assembly: fibrillogenesis is driven by decisive dimer-dimer interactions. Current Opinion in Structural Biology, 8: 177-185.

6. Angelides KJ, Smith KE \& Tokeda M (1989.) Assembly and exchange of intermediate filament proteins in neurons: neurofilaments are dynamic structures. J ournal of Cell Biology, 108: 1495-1506.

7. Vikstrom KL, Borisy GG \& Goldman RD (1989). Dynamic aspects of intermediate filament networks in BHK-21 cells. Proceedings of the National Academy of Sciences, USA, 86: 549-553.

8. Miller RA, Vikstrom $K \&$ Goldman RD (1991). Keratin incorporation into intermediate filament networks is a rapid process. J ournal of Cell Biology, 113: 843855.

9. Nakamura $\mathrm{Y}$, Takeda $\mathrm{M}$, Angelides $\mathrm{KJ}$, Tada K, Hariguchi S \& Nishimura T (1991). Assembly, disassembly, and subunit exchange of glial fibrillary acidic protein. Glia, 4: 101-110.

10. Vikstrom KL, Lim S-S, Goldman RD \& Borisy GG (1992). Steady state dynamics of intermediate filament networks. J ournal of Cell Biology, 118: 121-129.
11. Hatzfeld M \& Weber K (1992). A synthetic peptide representing the consensus sequence motif at the carboxy-terminal end of the rod domain inhibits intermediate filament assembly and disassembles preformed filaments. J ournal of Cell Biology, 116: 157-166.

12. Evans RM \& Fink LM (1982). An alteration in the phosphorylation of vimentin-type intermediate filaments is associated with mitosis in cultured mammalian cells. Cell, 29: 43-52.

13. Celis J E, Larsen PM, Fey SJ \& Celis A (1983). Phosphorylation of keratin and vimentin polypeptides in normal and transformed mitotic human epithelial amnion cells: behavior of keratin and vimentin filaments during mitosis. J ournal of Cell Biology, 97: 1429-1434.

14. Ottaviano $Y \&$ Gerace L (1985). Phosphorylation of the nuclear lamins during interphase and mitosis. J ournal of Biological Chemistry, 260: 624-632.

15. Chou $\mathrm{Y}-\mathrm{H}$, Rosevear E \& Goldman R (1989). Phosphorylation and disassembly of intermediate filaments in mitotic cells. Proceedings of the National Academy of Sciences, USA, 86: 1885-1889.

16. Inagaki $M$, Gonda $Y$, Nishizawa K, Kitamura S, Sato C, Ando S, Tanabe K, Kikuchi K, Tsuiki S \& Nishi Y (1990). Phosphorylation sites linked to glial filaments disassembly in vitro is located in a non- $\alpha$ helical head domain. J ournal of Biological Chemistry, 265: 4722-4729.

17. Chou $Y-H$, Bischoff J R, Beach $D \&$ Goldman RD (1990). Intermediate filament reorganization during mitosis is mediated by $\mathrm{p} 34^{\mathrm{cdc} 2}$ phosphorylation of vimentin. Cell, 62: 1063-1071.

18. Donato R (1991). Perspectives in S-100 protein biology. Cell Calcium, 12: 713-726.

19. Zimmer DB, Cornwall EH, Landar A \& Song W (1995). The S100 protein family: history, function, and expression. Brain Research Bulletin, 37: 417-429.

20. Schäfer BW \& Heizmann CW (1996). The S100 family of EF-hand calcium-binding proteins: functions and pathology. Trends in Biochemical Sciences, 21: 134-140.

21. Heizmann CW \& Cox J A (1998). New perspectives on S100 proteins: a multi-functional $\mathrm{Ca}^{2+}, \mathrm{Zn}^{2+}$ - and $\mathrm{Cu}^{2+}$-binding protein family. Biometals, 11: 383-397.

22. Donato R (1999). Functional roles of S100 proteins, calcium-binding proteins of the EF-hand type. Biochimica et Biophysica Acta, 1450: 191-231.

23. Isobe $T \& \&$ Okuyama $T$ (1978). The amino acid sequence of the S100 protein (PAP Ib protein) and its relation to the calcium binding proteins. European J ournal of Biochemistry, 89: 379-388.

24. Isobe $T \& \&$ Okuyama $T$ (1981). The amino acid sequence of the $\alpha$-subunit in bovine brain S100a protein. European J ournal of Biochemistry, 116: 79-86.

25. Rambotti MG, Saccardi C, Spreca A, Aisa MC, Giambanco I \& Donato R (1989). Immunocytochemical localization of S100b protein in olfactory and supporting cells of lamb olfactory epithelium. J ournal of Histochemistry and Cytochemistry, 37: 18251889.

26. Rambotti $M G$, Spreca $A$, Leoncini $P$, Estenoz M, Costantino-Ceccarini $E$, Giambanco I \& Donato R (1990). Detection of S100b protein in triton-cytoskeletons: an immunocytochemical study on cultured Schwann cells. J ournal of Histochemistry and Cytochemistry, 38: 15831589.

27. Sorci G, Agneletti AL, Bianchi R \& Donato $R$ (1998). Association of S100B with intermediate filaments and microtubules in glial cells. Biochimica et Biophysica Acta, 1448: 277-289.

28. Sorci G, Bianchi R, Giambanco I, Rambotti 
MG \& Donato R (1999). Replicating myoblasts and fused myotubes express the calcium-modulated proteins S100A1 and S100B. Cell Calcium, 25: 93-106.

29. Haimoto H \& Kato K (1988). S100ao $(\alpha \alpha)$ protein in cardiac tissue. Isolation from human cardiac muscle and ultrastructural localization. European J ournal of Biochemistry, 171: 409-415.

30. Donato R, Giambanco I, Aisa MC, Di Geronimo G, Ceccarelli P, Rambotti MG \& Spreca A (1989). Cardiac $S 100 a_{0}$ protein: purification by a simple procedure and related immunocytochemical and immunochemical studies. Cell Calcium, 10: 8192.

31. Drohat AC, Amburgey J C, Abildgaard F, Starich MR, Baldisseri D \& Weber D (1996). Solution structure of rat apoS100B (Bß) as determined by NMR spectroscopy. Biochemistry, 35: 11577-11588.

32. Kilby PM, Van Eldik LJ \& Roberts GCK (1996). The solution structure of the bovine S100B protein dimer in the calcium free state. Structure, 4: 1041-1052.

33. Matsumura $H$, Shiba $T$, Inoue $T$, Harada $S$ \& Kai Y (1998). A novel mode of target recognition suggested by the $2.0 \AA$ structure of holo S100B from bovine brain. Structure, 6: 233-241.

34. Smith SP \& Shaw GS (1997). Assignment and secondary structure of calcium-bound human S100B. J ournal of Biomolecular NMR, 10: 77-88.

35. Potts BCM, Smith J, Akke M, Macke TJ, Okazaki K, Hidaka H, Case DA \& Chazin WJ (1995). The structure of calcyclin reveals a novel homodimeric fold for $\mathrm{S} 100$ $\mathrm{Ca}^{2+}$-binding proteins. Nature Structural Biology, 2: 790-796.

36. Brodersen $D E$, Etzerodt $M$, Madsen $P$, Celis JE, Thøgersen HC, Nyborg J \& Kjildgaard M (1998). EF-hands at atomic resolution: the structure of human psoriasin (S100A7) solved by MAD phasing. Structure, 6: 477-489.

37. Drohat AC, Baldisseri DM, Rustandi RR \& Weber DJ (1998). Solution structure of calcium-bound rat S100B (Bß) as determined by NMR spectroscopy. Biochemistry, 37: 2729-2740.

38. Smith SP \& Shaw G (1998). A novel calcium-sensitive switch revealed by the structure of human S100B in the calciumbound form. Structure, 6: 211-222.

39. Kuboniwa H, Thrando N, Grzesiek S, Ren $H$, Klee CB \& BaxA (1995). Solution structure of calcium-free calmodulin. Nature Structural Biology, 9: 768-776.

40. Meador WE, Means AR \& Quiocho FA (1992). Recognition by calmodulin: $2.4 \AA$ structure of a calmodulin peptide complex. Science, 257: 1251-1255.

41. Ikura M, Chou GM, Gronengorg AM, Zhu G, Klee CB \& BaxA (1992). Solution structure of a calmodulin-target peptide complex by multidimensional NMR. Science, 256: 632-638.

42. Endo $T \&$ Hidaka $H$ (1983). Effect of $S 100$ protein on microtubule assembly-disassembly. FEBS Letters, 161: 235-238.

43. Donato R (1983). Effect of S100 protein on assembly of brain microtubule proteins in vitro. FEBS Letters, 162: 310-313.

44. Donato R (1985). Calcium-sensitivity of brain microtubule proteins in the presence of S100 proteins. Cell Calcium, 6: 343-361.

45. Donato R (1988). Calcium-independent, $\mathrm{pH}$-regulated effects of S100 proteins on assembly-disassembly of brain microtubule protein in vitro. J ournal of Biological Chemistry, 263: 106-110.

46. Baudier J, Briving C, Deinum J, Kaglid K, Sorskog L \& Wallin M (1982). Effect of S100 proteins and calmodulin on $\mathrm{Ca}^{2+}$ induced disassembly of brain microtubule proteins in vitro. FEBS Letters, 147: 165167.

47. Donato R, Giambanco I \& Aisa MC (1989). Molecular interaction of S100 proteins with microtubule proteins in vitro. J ournal of Neurochemistry, 53: 566-571.

48. Zimmer DB \& Landar A (1995). Analysis of S100A1 expression during skeletal muscle and neuronal cell differentiation. J ournal of Neurochemistry, 64: 27272736.

49. Bomsel $M$, Parton R, Kuznetsov SA, Schroer TA \& Gruenberg J (1990). Microtubule- and motor-dependent fusion in vitro between apical and basolateral endocytic vesicles from MDCK cells. Cell, 62: 719-731.

50. Gruenberg J, Griffiths $G$ \& Howell KE (1989). Characterization of early endosomes and putative endocytic carrier vesicles in vivo and with an assay of vesicle fusion in vitro. J ournal of Cell Biology, 108: 1301-1316.

51. Breitfeld PP, McKinnon WC \& Mostov KE (1990). Effect of nocodazole on vesicular traffic to the apical and basolateral surfaces of polarized MDCK cells. J ournal of Cell Biology, 111: 2365-2373.

52. Rambotti MG, Giambanco I, Spreca A \& Donato R (1999). S100B and S100A1 proteins in bovine retina: their calcium-dependent stimulation of a membranebound guanylate cyclase activity as investigated by ultracytochemistry. Neuroscience, 92: 1089-1101.
53. Bianchi $\mathrm{R}$, Giambanco I \& Donato $\mathrm{R}$ (1993). S100 protein, but not calmodulin, binds to the glial fibrillary acidic protein and inhibits its polymerization in a $\mathrm{Ca}^{2+}$ dependent manner. J ournal of Biological Chemistry, 268: 12669-12674.

54. Bianchi R, Verzini M, Garbuglia M, Giambanco I \& Donato R (1994). Mechanism of S100 protein-dependent inhibition of glial fibrillary acidic protein (GFAP) polymerization. Biochimica et Biophysica Acta, 1223: 354-360.

55. Bianchi $R$, Garbuglia $M$, Verzini $M$, Giambanco I, Spreca A \& Donato R (1995). S100 protein and annexin $\mathrm{Il}_{2}-\mathrm{p} 1 \mathrm{l}_{2}$ (calpactin I) act in concert to regulate the state of assembly of GFAP intermediate filaments in vitro. Biochemical and Biophysical Research Communications, 208: 910-918.

56. Garbuglia M, Verzini M, Giambanco I, Spreca A \& Donato R (1996). Effects of calcium-binding proteins $\left(\mathrm{S} 100 \mathrm{a}_{0}, \mathrm{~S} 100 \mathrm{a}\right.$, $\mathrm{S} 100 \mathrm{~b})$ on desmin assembly in vitro. FASEB J ournal, 10: 317-324.

57. Bianchi $R$, Garbuglia $M$, Verzini $M$, Giambanco I, Ivanenkov W, Dimlich RVW, J amieson J r GA \& Donato R (1996). S100 ( $\alpha$ and $ß$ )-binding peptide (TRTK-12) blocks S100/GFAP interaction: identification of a putative S100 target epitope within the head domain of GFAP. Biochimica et Biophysica Acta, 1313: 258-267.

58. Garbuglia M, Verzini $M$, Dimlich RVW, J amieson J r GA \& Donato R (1996). Characterization of type III intermediate filament regulatory protein target epitopes: S100 ( $($ and/or $\alpha$ ) binds the N-terminal head domain; annexin $\mathrm{Il}_{2}-\mathrm{p} \mathrm{Il}_{2}$ binds the rod domain. Biochimica et Biophysica Acta, 1313: 268-276.

59. Ivanenkov VV, Jamieson J $r$ GA Gruenstein E \& Dimlich RVW (1995). Characterization of S100b binding epitopes: identification of a novel target, the actin capping protein, Cap Z J ournal of Biological Chemistry, 270: 14651-14658.

60. Ivanenkov W, Dimlich RVW \& J amieson J r GA (1996). Interaction of S100a tein with the actin capping protein, CapZ: characterization of a putative $\mathrm{S} 100 \mathrm{a}_{0}$ binding site in CapZ $\alpha$-subunit. Biochemical and Biophysical Research Communications, 221: 45-50.

61. Raynal P \& Pollard HB (1994). Annexins: the problem of assessing the biological role for a gene family of multifunctional calcium- and phospholipid-binding proteins. Biochimica et Biophysica Acta, 1197: 63-93.

62. Gerke V \& Moss SE (1997). Annexins and membrane dynamics. Biochimica et Bio- 
physica Acta, 1357: 129-154.

63. Garbuglia M, Verzini M \& Donato R (1998). Annexin VI binds to S100Al and S100B and blocks the ability of S100A1 and S100B to inhibit desmin and GFAP assemblies into intermediate filaments. Cell Calcium, 24: 177-191.

64. Garbuglia M, Verzini M, Rustandi RR, Osterloh D, Weber DJ , Gerke V \& Donato $R$ (1999). Role of the C-terminal extension in the interaction of S100A1 with GFAP, tubulin, the S100A1- and S100B-inhibitory peptide, TRTK-12, and a peptide de- rived from $\mathrm{p} 53$, and the S100A1 inhibitory effect on GFAP polymerization. Biochemical and Biophysical Research Communications, 254: 36-41.

65. Osterloh $\mathrm{D}$, Ivanenkov $\mathrm{W} \&$ Gerke $\mathrm{V}$ (1998). Hydrophobic residues in the Cterminal extension of S100A1 are essential for target protein binding not for dimerization. Cell Calcium, 24: 137-151.

66. Ziegler DR, Innocente CE, Leal RB, Rodnight R \& Gonçalves CA (1998). The S100B protein inhibits phosphorylation of GFAP and vimentin in a cytoskeletal frac- tion from immature rat hippocampus. Neurochemical Research, 23: 1259-1263.

67. Ueda S, Gu XF, Whitaker-Azmitia PM, Naruse I \& Azmitia EC (1994). Neuro-glial neurothrophic interaction in the S-100ß retarded mutant mouse (Polydactyly Nagoya). I. Immunocytochemical and neurochemical studies. Brain Research, 633 : 275-283.

68. Donato R (1986). S100 proteins. Cell Calcium, 7: 123-145. 